\title{
High Incidence of Sporadic Creutzfeldt-Jakob Disease in Slovenia in 2015: A Case Series
}

\author{
Tomaž Rus $^{a} \quad$ Bogdan Lorber ${ }^{a} \quad$ Maja Trošt ${ }^{a}$ e $\quad$ Srečko Dobrecovičb \\ Nuška Čakš Jager ${ }^{c}$ Mara Popovićd Milica G. Kramberger ${ }^{a, e}$ \\ a Department of Neurology, Ljubljana University Medical Centre, Ljubljana, Slovenia; \\ ${ }^{\mathrm{b}}$ Institute of Radiology, Ljubljana University Medical Centre, Ljubljana, Slovenia;

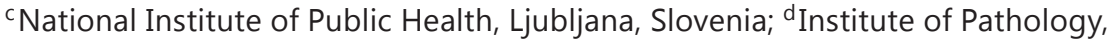 \\ Medical Faculty, University of Ljubljana, Ljubljana, Slovenia; e Medical Faculty, \\ University of Ljubljana, Ljubljana, Slovenia
}

\author{
Keywords \\ Sporadic Creutzfeldt-Jakob disease $\cdot$ Incidence $\cdot$ Case series
}

\section{Abstract}

Background: Creutzfeldt-Jakob disease (CJD) is a rare fatal neurodegenerative disorder presenting with rapid cognitive decline and additional signs. The clinical characteristics of an increasing number of sporadic CJD (sCJD) patients admitted to the Ljubljana University Medical Centre are presented as well as the incidence of SCJD in Slovenia in 2015 compared to previous years. Methods: We investigated patients presenting with rapidly progressive dementia and at least one additional sign. The diagnosis was made based on clinical diagnostic criteria and an autopsy was performed in all cases. Data on definite SCJD cases in Slovenia since 1999 were obtained and its incidence was calculated. Results: Eight patients with definite SCJD died in 2015 in Slovenia (incidence: 3.89 cases per million). The long-term incidence 1999 was 1.67 per million. Conclusions: The incidence of SCJD was considerably higher in 2015. It reflects fluctuations in sporadic cases of this rare disease. The rising trend might indicate a previous underestimation and better recognition of the disease. 


\section{Introduction}

Creutzfeldt-Jakob disease (CJD) is a fatal neurodegenerative disease caused by a misfolded cellular protein named prion protein or $\operatorname{PrP}^{\mathrm{Sc}}$ [1]. There are four subtypes of CJD: familial, iatrogenic, variant, and sporadic (sCJD) [2], the last being most common (85\% of CJD cases) [3].

The classic presentation of $\mathrm{sCJD}$ is a rapidly progressive dementia with ataxia, extrapyramidal signs, behavioural problems, and myoclonus in the advanced stage [4]. Cognitive decline is the most common initial presentation (in 35\% of patients). The first symptom can also be cerebellar dysfunction and behavioural or constitutional symptoms in approximately $17.5 \%$, respectively. Motor, sensory, and visual functions are rarely affected in the early stage [5]. Myoclonus usually appears late, and akinetic mutism is the usual presentation of advanced disease.

The first presentation may mimic several other well-defined neurological syndromes [4]. There are cases presenting as isolated aphasia, catatonia, muscle atrophy, and fasciculations or with acute/subacute unilateral symptoms mimicking stroke, etc. [6-9].

Its definite diagnosis, proof of the presence of $\mathrm{PrP}^{\mathrm{Sc}}$ in the brain, is based on microscopic examination of brain tissue applying anti-PrP antibodies and immunohistochemistry [10]. Antemortem diagnosis is based on clinical criteria [11-13]; according to the European MRI-CJD criteria, possible CJD is diagnosed if a patient has had progressive dementia lasting less than 2 years and at least one of the following symptoms/signs: myoclonus, pyramidal/ extrapyramidal dysfunction, visual/cerebellar dysfunction, or akinetic mutism. Additionally, the presence of one of three laboratory test results supports the clinical diagnosis of probable CJD: (1) typical EEG changes with periodic sharp wave complexes, (2) elevated protein 14-3-3 levels in the cerebrospinal fluid (CSF), or (3) typical MRI abnormality (hyperintensity on FLAIR or DWI sequences in the putamen and caudate nucleus or in at least two cortical regions) [11]. Alternative causes of rapidly progressing dementia should be excluded.

The disease has a short course; median survival is reported to be 3.5-6.5 months, and $90 \%$ of Caucasian patients die within 1 year [14-16]. sCJD is a rare disease with an incidence reported at 1.39 per million [3]. Mortality rates are similar in most countries [17].

In many countries, mandatory reporting legislation came into force after cases of variant CJD were reported in the UK in 1996 as a consequence of ingestion of bovine spongiform encephalopathy-infected meat products [18]. In Slovenia, prion disease surveillance was launched in 1995; however, mandatory reporting to the National Institute of Public Health (NIPH) started in 1999, and obligatory autopsy in $2001[19,20]$.

The aim of our report is to present the clinical characteristics of the SCJD patients admitted to the Memory Clinic at the Department of Neurology, Ljubljana University Medical Centre (UMC Ljubljana), in 2015 and to evaluate the incidence of sCJD in Slovenia in 2015 compared to previous years.

\section{Methods}

In this retrospective study, patients presenting with rapidly progressive dementia and at least one additional sign admitted to the Memory Clinic at the Department of Neurology, UMC Ljubljana, in 2015 were included. All of them underwent extensive medical investigation to exclude treatable causes of cognitive decline. Extended blood tests including antineuronal antibodies, paraneoplastic antibodies, tumour markers, and immunoserologic tests; screening tests for infectious diseases; EEG; brain MRI (1.5 T, in 1 case 3 T; including T1, T2, FLAIR, DWI, and apparent diffusion coefficient); and CSF analysis including 14-3-3 protein, tau, p-tau, and 
Table 1. Demographic characteristics, disease duration, cerebrospinal fluid 14-3-3 protein status, and genotype of patients with sporadic Creutzfeldt-Jakob disease in 2015

\begin{tabular}{llllll}
\hline Patient ID & Age, years & Sex & Disease duration, days & Protein 14-3-3 & PRNP genotype \\
\hline$\# 1$ & 67 & M & 50 & positive & MM129, NM \\
$\# 2$ & 85 & $\mathrm{~F}$ & 75 & positive & MM129, NM \\
$\# 3$ & 76 & $\mathrm{M}$ & 41 & positive & MM129, NM \\
$\# 4^{\mathrm{a}}$ & 58 & $\mathrm{~F}$ & 159 & positive & VV129, NM \\
$\# 5$ & 79 & $\mathrm{~F}$ & 53 & positive & MM129, NM \\
$\# 6$ & 70 & $\mathrm{~F}$ & 241 & positive & MM129, NM \\
$\# 7$ & 81 & $\mathrm{~F}$ & N/A & negative & MM129, NM \\
$\# 8$ & 72 & $\mathrm{~F}$ & N/A & positive & MM129, NM \\
$\# 9$ & 56 & $\mathrm{M}$ & N/A & N/A & VV129, NM \\
\hline
\end{tabular}

N/A, not available; PRNP, prion protein gene; NM, no mutation. ${ }^{a}$ Patient died in 2016, not included in 2015 incidence calculation.

amyloid- $\beta_{1-42}$ were performed. In certain cases, additional tests were performed, i.e., ${ }^{18}$ F-FDGPET and neuropsychological examination. There were no interventions for research purposes. The European MRI-CJD Consortium Criteria [11] were used to make the clinical diagnosis of possible or probable sCJD. Autopsies were performed on all patients; brain tissue underwent histopathological and immunohistochemical analysis to confirm the presence of $\mathrm{PrP}^{\mathrm{Sc}}$ and to exclude variant CJD. Analysis of the PRNP (prion protein) gene was performed to confirm/ exclude familial CJD and to detect codon 129 polymorphism. Detailed personal histories were obtained to rule out potential iatrogenic cases.

All cases with proven sCJD admitted in 2015 are presented in this report; however, due to epidemiological reasons, only patients that died in 2015 were included in the 2015 incidence calculation.

We also acquired data from the NIPH on patients with definite SCJD that died in 2015 in Slovenia. Histopathological, immunohistochemical, and genetic analyses were available for all cases. Any available medical documentation on these patients was evaluated.

We acquired NIPH data on the yearly reported numbers of definite SCJD cases in Slovenia since 1999, when mandatory reporting started [19]. To analyse the incidence trend, linear regression was used. The slope of the linear regression line is presented with $95 \%$ confidence intervals. The coefficient of determination $\left(R^{2}\right)$ was calculated using GraphPad Prism version 6 for Windows (GraphPad Software, San Diego, CA, USA). A $p$ value $<0.05$ was considered statistically significant.

\section{Results}

In 2015, there were 5 patients admitted to the Department of Neurology, UMC Ljubljana, fulfilling the diagnostic criteria for possible or probable sCJD. Four of them died in 2015 and one at the beginning of 2016 (included in the 2016 incidence calculation). Autopsies were performed and they were all proven positive for $\mathrm{PrP}^{\mathrm{Sc}}$. Four additional definite SCJD cases were reported by other Slovenian hospitals/pathologists to the NIPH in 2015. Genetic CJD was ruled out by PRNP gene analysis and there were no pathological characteristics of variant CJD. Based on the detailed personal histories, iatrogenic CJD was not suspected.

There were 6 females and 3 males with a mean age of $71.6 \pm 10.0$ years. There was no specific geographic pattern identified. The average duration of the disease (since the first 
Table 2. MRI, EEG, brain ${ }^{18}$ F-FDG-PET, and CSF tau results/values of patients with sporadic Creutzfeldt-Jakob disease in 2015

\begin{tabular}{|c|c|c|c|c|}
\hline $\begin{array}{l}\text { Patient } \\
\text { ID }\end{array}$ & MRI & EEG & Brain ${ }^{18}$ F-FDG-PET & $\begin{array}{l}\text { CSF tau, } \\
\mathrm{pg} / \mathrm{mL}\end{array}$ \\
\hline$\# 1$ & $\begin{array}{l}\text { FLAIR/DWI hyperintense right frontal } \\
\text { cortex, bilateral gyri cinguli, bilateral caudate } \\
\text { nuclei, and right anterior putamen; } \\
\text { performed twice in } 20 \text { days; clear } \\
\text { progression }\end{array}$ & Typical (PSWC) & $\begin{array}{l}\text { Hypometabolism in right frontal } \\
\text { and posterior parietal cortices } \\
\text { as well as the cerebellum; } \\
\text { hypermetabolism in basal } \\
\text { ganglia }\end{array}$ & 2,280 \\
\hline$\# 2$ & $\begin{array}{l}\text { FLAIR/DWI hyperintense right frontal } \\
\text { operculum and right insular cortex; } \\
\text { performed twice in } 26 \text { days; clear } \\
\text { progression }\end{array}$ & Typical (PSWC) & $\begin{array}{l}\text { Hypometabolism in cortex of } \\
\text { right hemisphere and right } \\
\text { basal ganglia }\end{array}$ & 2,500 \\
\hline \#3 & $\begin{array}{l}\text { FLAIR/DWI hyperintense left caudate } \\
\text { nucleus, putamen, insular cortex, left frontal } \\
\text { operculum, and bilateral limbic cortices; } \\
\text { performed twice in } 8 \text { days; no progression }\end{array}$ & Typical (PSWC) & $\begin{array}{l}\text { Hypometabolism in left parietal } \\
\text { and frontal cortices and left } \\
\text { putamen }\end{array}$ & 2,270 \\
\hline$\# 4^{\mathrm{a}}$ & $\begin{array}{l}\text { FLAIR/DWI hyperintense caudate nuclei, } \\
\text { putamina, thalami, and limbic cortices } \\
\text { bilaterally; performed twice in } 23 \text { days; clear } \\
\text { progression }\end{array}$ & $\begin{array}{l}\text { Not typical } \\
\text { (progressive } \\
\text { encephalopathy } \\
\text { with slow activity) }\end{array}$ & $\begin{array}{l}\text { Pronounced hypometabolism } \\
\text { in basal ganglia bilaterally and } \\
\text { cortex of the left hemisphere }\end{array}$ & 2,280 \\
\hline \#5 & $\begin{array}{l}\text { FLAIR/DWI hyperintense caudate nucleus, } \\
\text { putamen, and thalamus; cortical ribboning }\end{array}$ & Typical (PSWC) & $\mathrm{N} / \mathrm{A}$ & 2,270 \\
\hline \#6 & $\begin{array}{l}\text { FLAIR/DWI hyperintense bilateral caudate } \\
\text { nuclei, putamina, cingulate gyri, and insular } \\
\text { cortices; right temporal, frontal in the } \\
\text { parietal cortex }\end{array}$ & $\mathrm{N} / \mathrm{A}$ & $\mathrm{N} / \mathrm{A}$ & $\mathrm{N} / \mathrm{A}$ \\
\hline \#7 & $\begin{array}{l}\text { FLAIR/DWI asymmetrical hyperintense } \\
\text { bilateral temporal, frontal, occipital, and } \\
\text { parietal cortices, cingulate gyri bilaterally, } \\
\text { and caudate nuclei bilaterally; putamina less } \\
\text { evident; performed twice, clear progression }\end{array}$ & $\mathrm{N} / \mathrm{A}$ & $\mathrm{N} / \mathrm{A}$ & $\mathrm{N} / \mathrm{A}$ \\
\hline \#8 & $\mathrm{N} / \mathrm{A}$ & $\mathrm{N} / \mathrm{A}$ & $\mathrm{N} / \mathrm{A}$ & $\mathrm{N} / \mathrm{A}$ \\
\hline \#9 & $\begin{array}{l}\text { DWI hyperintense bilateral temporal cortices } \\
\text { and right parietal cortex; no FLAIR changes }\end{array}$ & $\mathrm{N} / \mathrm{A}$ & $\mathrm{N} / \mathrm{A}$ & $\mathrm{N} / \mathrm{A}$ \\
\hline
\end{tabular}

CSF, cerebrospinal fluid; N/A, not available; FLAIR, fluid-attenuated inversion recovery; DWI, diffusion-weighted imaging;

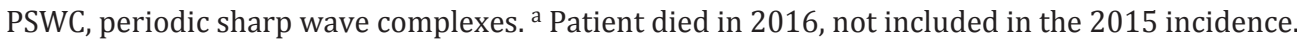

symptoms) was $103.2 \pm 80.1$ days. At 8 cases, the incidence of sCJD in 2015 was 3.89 cases per million. The patients' demographic characteristics, protein 14-3-3 status, and PRNP genotype are presented in Table 1 . The MRI, EEG, brain ${ }^{18}$ F-FDG-PET, and CSF tau results are presented in Table 2.

We present the clinical data on the 5 patients diagnosed at the UMC Ljubljana (patients 1-5). The following short reports highlight their clinical characteristics and laboratory results. Their MRI, EEG, protein 14-3-3, CSF tau, p-tau, amyloid- $\beta_{1-42}$, and genetic results are presented in the tables above. In all 5 cases, the disease progressed to akinetic mutism. 


\section{Case 1}

A 67-year-old man presented with rapidly progressive cognitive decline 10 days before admission. His first reported symptom was difficulty playing accordion.

At admission, he was well oriented in time, space, and person, but impairment of recall and apparent dyscalculia was noted on testing. His Mini-Mental State Examination (MMSE) score was $23 / 30$. The baseline neurological examination was otherwise unremarkable. His blood tests, basic CSF analysis, rheumatologic tests, and tumour markers were unremarkable. Within a few days, he developed bilateral limb ataxia, within 2 weeks stimulus-induced myoclonus evolved, and in the third week the patient became severely disoriented in time and space, and confabulations and hallucinations evolved.

\section{Case 2}

In an 85-year-old female who presented with an acute onset of left-sided hemiparesis and hemihypaesthesia, ischaemic stroke was first suspected. Left-sided upper limb ataxia evolved soon after admission, and 2 days later left-sided stimulus-induced myoclonus and stereoagnosis emerged; the symptoms progressed to alien-limb syndrome. Cognition was initially intact; 2 weeks after the first symptoms had appeared, her MMSE score was 26/30.

Her blood tests were unremarkable. There were slightly higher values of CSF protein 0.65 $\mathrm{g} / \mathrm{L}$ ). Within 3 weeks she had developed generalized rigidity; she became increasingly somnolent in the fourth week, and within 2 months she presented with the full-blown akinetic mutism.

Case 3

A 76-year-old male experienced balance problems immediately after radioactive iodine treatment for hyperthyroidism. In the following few days, problems with precise movements as well as quick jerks in the right hand evolved. A neurological examination revealed cerebellar dysarthria, gait ataxia, right-sided limb ataxia, and occasional myoclonus. The ataxia and myoclonus progressed over a period of 2 weeks, and there was a rapid cognitive decline which was not present at admission. Within 4 weeks he was unable to walk, had problems breathing, and had continuous hiccups.

His blood tests were unremarkable, but the CSF protein level was slightly elevated 0.56 g/L). Paraneoplastic, antineuronal, thyroglobulin, and antithyroid peroxidase antibodies were negative.

\section{Case 4}

A 58-year-old female experienced subacute onset of balance problems followed by forgetfulness, vertigo, and diplopia. The symptoms progressed within 3 months. On admission, her MMSE score was 20/30; she had central nystagmus, bilaterally positive primitive reflexes, gait ataxia, and no limb ataxia.

Her blood tests, CSF analysis, and paraneoplastic and antineuronal antibodies in CSF and serum were unremarkable. Four weeks after admission, choreatic movements, hallucinations, and illusions evolved.

\section{Case 5}

A 79-year-old female presented with subacute onset of difficulties with object recognition and short-term memory, which started a month before admission. Two weeks from onset, balance problems evolved, followed by well-defined non-threatening visual hallucinations. At admission, her consciousness was preserved, but she was aphasic and psychomotor

agitation was noted, as well as perioral dyskinesia and spontaneous and stimulus-evoked myoclonus. During hospitalization she was agitated, myoclonus progressed, and choreatic movements evolved. Her blood tests and CSF analysis were negative. 
Fig. 1. Incidence of sporadic Creutzfeldt-Jakob disease in Slovenia 1999-2016. The linear regression line is shown.

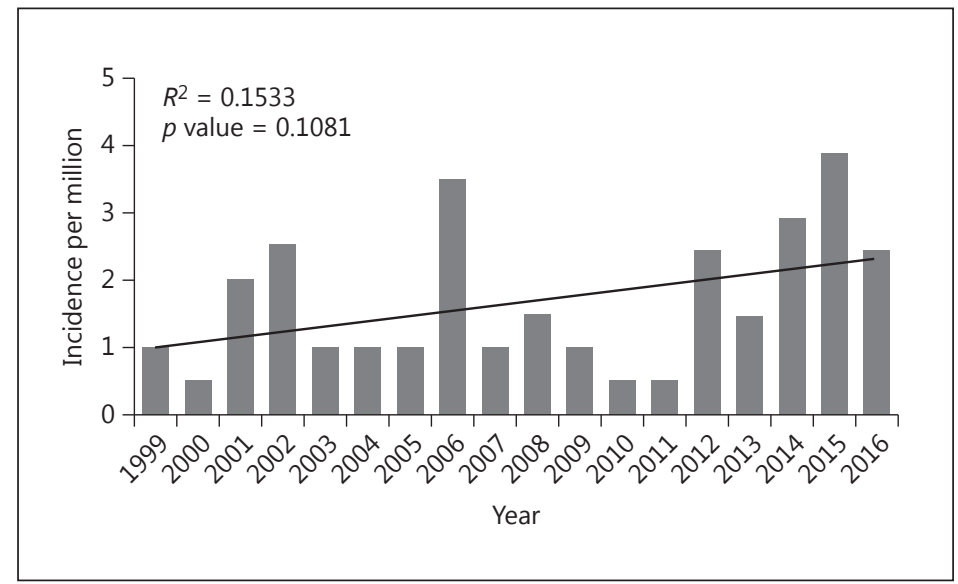

Incidence of SCJD in Slovenia 1999-2016

The incidence of definite SCJD in the period 1999-2016 was 1.67 per million with pronounced annual fluctuations (Fig. 1). Peaks were reported in 2006 (7 cases), 2014 (6 cases), and 2015 (8 cases). In the years 2000, 2010, and 2011 there was only 1 case reported. There is a trend for a rising incidence: 0.077 per year per million $(95 \%$ confidence interval: -0.019 to 0.172$)$. However, this trend is not significant $(p=0.1081)$ and the coefficient of determination is low $\left(R^{2}=0.1533\right)$.

\section{Discussion}

Eight cases overall or 3.89 cases per million represent an unusually high incidence of sCJD in Slovenia in 2015. The fluctuation in incidence in the studied period is not surprising, since it is a rare disease in a small population of approximately 2 million residents. Despite the fluctuation, which is reflected in a low coefficient of determination, a trend, although not significant, for an increasing incidence is indicated. One explanation for this trend could be a better recognition of the disease among physicians.

Our data show higher incidence rates than the published data by EuroCJD for the time period between 1993 and 2013 [17]. We only studied the time period since the mandatory reporting legislation of suspected SCJD cases came into force in 1999 [19].

The 5 cases from the UMC Ljubljana showed diverse clinical manifestations at the beginning of the disease: from rapid cognitive decline to balance problems (gait ataxia) and stroke-like syndrome that progressed to alien limb phenomena with pronounced rigidity (corticobasal syndrome [CBS]). In contrast to cognitive and cerebellar symptoms, which are common (13-46 and 14-65\%, respectively), motor manifestations are rare as a first presenting symptom $(6-8 \%)[5,21]$. There are occasional case reports of a stroke-like presentation of sCJD [8, 22-24]. To our knowledge, acute-onset stroke-like symptoms that progressed to CBS have been described only once before [22]. Approximately 40 cases of CBS presentations of sCJD have been published [25].

Some patients had MRI performed twice. Consecutive MRI revealed a progression of the radiological changes, consistent with previously published data [26]. In addition, the EEG changes intensified in time in all cases and in all but one progressed. Repeat EEG and MRI should be considered when results are negative in deteriorating patients.

The MRI and ${ }^{18}$ F-FDG-PET results were mostly concordant, as expected based on previously published data [27]. However, metabolic changes were more pronounced than struc- 
tural changes, and also in comparison to other neurodegenerative diseases. Consistent with previously published data [27], the ${ }^{18}$ F-FDG-PET changes were mostly asymmetrical. In case 2 , the ${ }^{18} \mathrm{~F}$-FDG-PET result was typical for CBS and hypometabolism was prominent, in contrast to the mild changes on MRI.

In case 1 , the cause of basal ganglia hypermetabolism was discovered post mortem on histopathological examination, which revealed a somewhat paler substantia nigra and Lewy bodies in pigmented neurons of the substantia nigra, locus caeruleus, and dorsal nucleus of the vagal nerve, consistent with Parkinson disease (PD) [28]. Besides PD pathology there was also evidence of early tauopathy and TDP-43 proteinopathy. Coexistence of SCJD with different neurodegenerative pathologies including PD has been described before in a few case reports $[29,30]$.

Case 3 was unusual, since balance problems started immediately after radioactive iodine application. We could not find any causative connection and it was probably a coincidence. However, there is a published case of deterioration immediately after surgery; in that case report, a detailed history revealed that discrete symptoms had been present before the procedure [23].

All 5 patients presenting to our clinic had positive CSF 14-3-3 and CSF tau values clearly above the cut-off value for CJD [31], which was expected, since both are biomarkers of neuronal damage and the patients were already evidently disabled when CSF was obtained.

Recently, another highly specific test for CJD, the real-time quaking-induced conversion (RT-QuIC) assay for detection of $\mathrm{PrP}^{\mathrm{Sc}}$ in CSF or in olfactory mucosal brushing, was invented [32]. Using appropriate samples and procedures, this method is reported to achieve a high specificity and sensitivity approaching $100 \%$ [33]. It is a very promising test, but currently available only at certain centres.

One limitation of this study is that we calculated the incidence based on pathologically proven cases of sCJD. There were some patients reported as possible or probable CJD cases to the NIPH that did not have an autopsy performed. Therefore, the incidence reported might be underestimated. Another limitation of studying rare diseases like SCJD might be insufficient recognition among physicians.

This study confirms the broad variety of possible early presentations of a rare disease that is, SCJD - and emphasizes the importance of a comprehensive diagnostics of patients with rapidly progressive dementia. Early identification and regular reporting of new cases of clinically suspected CJD with subsequent autopsies are important for epidemiological as well as research purposes.

\section{Statement of Ethics}

According to national legislation, the NIPH has an obligation to collect, analyse, and publish data on infectious diseases [19].

\section{Disclosure Statement}

The authors declare no conflicts of interest. 


\section{References} Creutzfeldt-Jakob disease. Geneva, WHO, 2003. http://whqlibdoc.who.int/publications/2003/9241545887. pdf.

-3 Ladogana A, Puopolo M, Croes EA, Budka H, Jarius C, Collins S, Klug GM, Sutcliffe T, Giulivi A, Alperovitch A, Delasnerie-Laupretre N, Brandel JP, Poser S, Kretzschmar H, Rietveld I, Mitrova E, Cuesta Jde P, MartinezMartin P, Glatzel M, Aguzzi A, Knight R, Ward H, Pocchiari M, van Duijn CM, Will RG, Zerr I: Mortality from Creutzfeldt-Jakob disease and related disorders in Europe, Australia and Canada. Neurology 2005;64:15861591.

4 Geschwind MD: Prion diseases. Continuum (Minneap Minn) 2015;21(Neuroinfectious Disease):1612-1638.

5 Rabinovici GD, Wang PN, Levin J, Cook L, Pravdin M, Davis J, DeArmond SJ, Barbaro NM, Martindale J, Miller BL, Geschwind MD: First symptom in sporadic Creutzfeldt-Jakob disease. Neurology 2006;66:286-287.

-6 Winton-Brown T, Doti I, Ting A, Atherton S, Mocellin R, Loyal S, Gaillard F, Velakoulis D: A case of CreutzfeldtJakob disease presenting as catatonia. J Clin Psychiatry 2016;77:e900-e901.

-7 Díaz-Díaz A, Hervás-García M, Amela-Peris R, García-Rodríguez JR: Muscle atrophy and fasciculations as a manifestation of sporadic Creutzfeldt-Jakob disease: a case report (in English, Spanish). Neurologia 2016, Epub ahead of print.

8 Patel S, Smallwood N, Abu HJ, Abousleiman Y: When is a stroke not a stroke? An unusual mimic presenting to AMU. Acute Med 2016;15:33-36.

-9 El Tawil S, Chohan G, Mackenzie J, Rowe A, Weller B, Will RG, Knight R: Isolated language impairment as the primary presentation of sporadic Creutzfeldt Jakob disease. Acta Neurol Scand 2017;135:316-323.

10 Budka H, Aguzzi A, Brown P, Brucher JM, Bugiani O, Gullotta F, Haltia M, Hauw JJ, Ironside JW, Jellinger K, et al: Neuropathological diagnostic criteria for Creutzfeldt-Jakob disease (CJD) and other human spongiform encephalopathies (prion diseases). Brain Pathol 1995;5:459-466.

11 Zerr I, Kallenberg K, Summers DM, Romero C, Taratuto A, Heinemann U, Breithaupt M, Varges D, Meissner B, Ladogana A, Schuur M, Haik S, Collins SJ, Jansen GH, Stokin GB, Pimentel J, Hewer E, Collie D, Smith P, Roberts H, Brandel JP, van Duijn C, Pocchiari M, Begue C, Cras P, Will RG, Sanchez-Juan P: Updated clinical diagnostic criteria for sporadic Creutzfeldt-Jakob disease. Brain 2009;132(pt 10):2659-2668.

$>12$ Vitali P, Maccagnano E, Caverzasi E, Henry RG, Haman A, Torres-Chae C, Johnson DY, Miller BL, Geschwind MD: Diffusion-weighted MRI hyperintensity patterns differentiate CJD from other rapid dementias. Neurology 2011;76:1711-1719.

13 WHO: Global surveillance, diagnosis and therapy of human transmissible spongiform encephalopathies: report of a WHO consultation. Geneva, Switzerland, 9-11 February 1998. Geneva, WHO, 1998. http://www. who.int/csr/resources/publications/bse/WHO_EMC_ZDI_98_9/en/.

14 Klug GM, Boyd A, Zhao T, Stehmann C, Simpson M, McLean CA, Masters CL, Collins SJ: Surveillance for Creutzfeldt-Jakob disease in Australia: update to December 2012. Commun Dis Intell Q Rep 2013;37:E115E120.

15 Jansen C, Parchi P, Capellari S, Ibrahim-Verbaas CA, Schuur M, Strammiello R, Corrado P, Bishop MT, van Gool WA, Verbeek MM, Baas F, van Saane W, Spliet WG, Jansen GH, van Duijn CM, Rozemuller AJ: Human prion diseases in the Netherlands (1998-2009): clinical, genetic and molecular aspects. PLoS One 2012;7:e36333.

16 Iwasaki Y: Creutzfeldt-Jakob disease. Neuropathology 2017;37:174-188.

17 Creutzfeldt-Jakob Disease International Surveillance Network: National CJD Research \& Surveillance Unit 1993-2013. http://www.eurocjd.ed.ac.uk/ (cited October 8, 2017).

-18 Will RG, Ironside JW, Zeidler M, Cousens SN, Estibeiro K, Alperovitch A, Poser S, Pocchiari M, Hofman A, Smith PG: A new variant of Creutzfeldt-Jakob disease in the UK. Lancet 1996;347:921-925.

19 Pravilnik o prijavi nalezljivih bolezni in posebnih ukrepih za njihovo preprečevanje in obvladovanje. Uradni list RS, No. 16/1999 (March 19, 1999).

20 Odredba o preventivnih ukrepih v zvezi s transmisivnimi spongiformnimi encefalopatijami. Uradni list RS, No. 2/2001 (January 12, 2001).

21 Brown P, Cathala F, Castaigne P, Gajdusek DC: Creutzfeldt-Jakob disease: clinical analysis of a consecutive series of 230 neuropathologically verified cases. Ann Neurol 1986;20:597-602.

-22 Necpál J, Stelzer M, Koščová S, Patarák M: A corticobasal syndrome variant of familial Creutzfeldt-Jakob disease with stroke-like onset. Case Rep Neurol Med 2016;2016:4167391.

23 Magny E, Sagot C, Cohen-Bittan J, Makdessi S, Bertrand A, Verny M, Boddaert J: Probable Creutzfeldt-Jakob disease mimicking a perioperative stroke in an elderly adult. J Am Geriatr Soc 2015;63:1268-1269.

-24 Damato V, Cuccagna C, Costantini EM, Gaudino S, Colosimo C, Parchi P, Servidei S, Luigetti M: Creutzfeldt-Jakob disease manifesting as stroke mimic in a 78-year-old patient: pitfalls and tips in the diagnosis. J Neurol Sci 2014;346:343-344.

25 Lee W, Simpson M, Ling H, McLean C, Collins S, Williams DR: Characterising the uncommon corticobasal syndrome presentation of sporadic Creutzfeldt-Jakob disease. Parkinsonism Relat Disord 2013;19:81-85.

-26 Cohen OS, Chapman J, Korczyn AD, Siaw OL, Warman-Alaluf N, Nitsan Z, Appel S, Kahana E, Rosenmann H, Hoffmann C: Clinical radiological correlation in E200K familial Creutzfeldt-Jakob disease. J Neural Transm (Vienna) 2016;123:1457-1462. 
27 Renard D, Vandenberghe R, Collombier L, Kotzki PO, Pouget JP, Boudousq V: Glucose metabolism in nine patients with probable sporadic Creutzfeldt-Jakob disease: FDG-PET study using SPM and individual patient analysis. J Neurol 2013;260:3055-3064.

28 Tripathi M, Dhawan V, Peng S, Kushwaha S, Batla A, Jaimini A, D’Souza MM, Sharma R, Saw S, Mondal A: Differential diagnosis of parkinsonian syndromes using F-18 fluorodeoxyglucose positron emission tomography. Neuroradiology 2013;55:483-492.

29 Laurencin C, Broussolle E, Streichenberger N, Thobois S, Quadrio I, Poisson A: Parkinson's with tardive Creutzfeldt-Jakob disease: when there is more to it than meets the eye. Rev Neurol (Paris) 2014;170:148-150.

-30 Haraguchi T, Terada S, Ishizu H, Sakai K, Tanabe Y, Nagai T, Takata H, Nobukuni K, Ihara Y, Kitamoto T, Kuroda S: Coexistence of Creutzfeldt-Jakob disease, Lewy body disease, and Alzheimer's disease pathology: an autopsy case showing typical clinical features of Creutzfeldt-Jakob disease. Neuropathology 2009;29:454-459.

31 Otto M, Wiltfang J, Cepek L, Neumann M, Mollenhauer B, Steinacker P, Ciesielczyk B, Schulz-Schaeffer W, Kretzschmar HA, Poser S: Tau protein and 14-3-3 protein in the differential diagnosis of Creutzfeldt-Jakob disease. Neurology 2002;58:192-197.

32 Atarashi R, Satoh K, Sano K, Fuse T, Yamaguchi N, Ishibashi D, Matsubara T, Nakagaki T, Yamanaka H, Shirabe S, Yamada M, Mizusawa H, Kitamoto T, Klug G, McGlade A, Collins SJ, Nishida N: Ultrasensitive human prion detection in cerebrospinal fluid by real-time quaking-induced conversion. Nat Med 2011;17:175-178.

33 Bongianni M, Orrù C, Groveman BR, Sacchetto L, Fiorini M, Tonoli G, Triva G, Capaldi S, Testi S, Ferrari S, Cagnin A, Ladogana A, Poleggi A, Colaizzo E, Tiple D, Vaianella L, Castriciano S, Marchioni D, Hughson AG, Imperiale D, Cattaruzza T, Fabrizi GM, Pocchiari M, Monaco S, Caughey B, Zanusso G: Diagnosis of human prion disease using real-time quaking-induced conversion testing of olfactory mucosa and cerebrospinal fluid samples. JAMA Neurol 2017;74:155-162. 